\title{
Access to health care in developing countries: breaking down demand side barriers
}

\author{
Acesso aos cuidados de saúde nos países em \\ desenvolvimento: rompendo barreiras contra a \\ demanda
}

\footnotetext{
1 Department of Balkan, Slavic and Oriental Studies, University of Macedonia Thessaloniki, Greece.

Correspondence O. O'Donnell Department of Balkan, Slavic and Oriental Studies, University of Macedonia. 156 Egnatia Street Thessaloniki, Greece. ood@uom.gr
}

\begin{abstract}
Effective health care interventions are underutilized in the developing world, and incomerelated disparities in use are large. The evidence concerning this access problem is summarized and its demand side causes are identified. Broad strategies that have been proposed to tackle the access problem through changes in economic incentives are considered. It is argued that there is a need to go beyond the identification of broad strategies to the design and evaluation of specific policy measures. Only through experimentation and evaluation will we learn what works in raising health care utilization, particularly among the poor in the developing world.
\end{abstract}

Health Services Accessibility; Developing Countries; Equity

\section{Introduction}

A large body of evidence confirms that many people in the developing world go without health care from which they could benefit greatly. The poor in developing countries are even less likely than the better off to receive effective health care. Concern for the level and distribution of health in the developing world demands that measures be taken to redress both facts. What are these measures? What policies can increase the utilization of effective health care, particularly by the poor in developing countries?

There are two sides to the access problem. On the supply side, good quality, effective health care may not be offered. On the demand side, individuals may not utilize services from which they could benefit. The two are obviously related. Poor quality care will arouse little interest from the public. A high level of demand, made effective by purchasing power, will induce the provision of quality care. Solving the access problem requires tackling both demand and supply side issues. Given the space constraint, this paper will concentrate on the demand side, although a recurring theme will be that the response to demand side measures is dependent on supply side conditions. There is an urgent need to establish mechanisms that can increase the availability and improve the quality of health care in the developing world. For present purposes, let us suppose that effective health care interventions can 
be delivered. What are the barriers that constrain access to this care, particularly among the poor, and what policy measures offer the greatest potential to break down these barriers?

In the next section (Access to Effective Health Care in Developing Countries: Evidence), evidence on access to effective health care in developing countries is reviewed. The third section (Why Are Effective Interventions Not Utilized?) identifies the main demand side barriers to access. The fourth section (Strategies to Raise Utilization of Effective Interventions) considers strategies that could potentially break down these barriers. The final section presents some key conclusions.

\section{Access to effective health care in developing countries: evidence}

Access to health care can be defined in a variety of ways. In its most narrow sense, it refers to geographic availability. A far broader definition identifies four dimensions of access: availability, accessibility, affordability, and acceptability 1 . Some define access as the opportunity to use health care; others draw no distinction between access and use.

This paper circumvents such discussions and proposes that the central concern is whether individuals that can potentially benefit from effective health care do in fact receive it. Health programs and systems should be evaluated against this objective through examination of the rate of utilization of effective health care among the population in need, which has been referred to as effective coverage 2 . In practice, it is often difficult to identify both the population in need and the effectiveness of the care on offer. Much of the evidence reviewed below refers simply to the rate of utilization of health care in the population.

\section{Effective interventions are not fully exploited}

There is ample evidence confirming that access to effective health care is a major problem in the developing world. Many millions of people suffer and die from conditions for which there exist effective interventions. Three diseases - diarrhea, pneumonia, and malaria - are responsible for $52 \%$ of child deaths worldwide. For each disease there is at least one effective prevention and one effective treatment ${ }^{3}$. The gap between the potential and actual benefits of health care is also large in the area of reproductive health. For example, in South Asia, less than half of pregnant women get an antenatal check-up, and only one-fifth of births are supervised by someone with medical training 3 . Coverage rates for antiretroviral thera- py for AIDS do not exceed $5 \%$ in low- and middleincome countries 3 .

Because of this gross underutilization of effective health care, there exist large unrealized health gains in developing countries. Child deaths could be cut by $63 \%$ worldwide if coverage rates of effective prevention and treatment interventions were to increase from current levels to $99 \% 4$. Raising coverage rates of maternal health interventions (the most important of which is essential obstetric care) to the same level would reduce maternal deaths by three-fourths 3 (preliminary estimates).

A multitude of factors is responsible for these missed opportunities to realize major gains in population health. On the demand side, cultural and educational factors may obscure the recognition of illness and the potential benefits from health care, while economic constraints may suppress utilization, even if benefits are recognized. It is estimated that deficient care seeking is a factor in $6-70 \%$ of child deaths 5 . In Bolivia, $60 \%$ of children who died during a study period were not taken for medical treatment during the fatal sickness episode 6 . The median study finding is that $23 \%$ of fatally ill children are not taken for treatment 5 .

On the supply side, appropriate interventions may not be provided at all, perhaps due to a lack of resources. The substantial gaps that exist between the actual health spending of many poor countries and the spending required to provide a package of essential health services suggest that lack of availability is the root of the problem in many instances 7 . It is important to recognize, however, that many effective interventions are not prohibitively expensive, even for very poor countries. For example, one half of avoidable child deaths in sub-Saharan Africa could be realized through home-delivered interventions 3 .

Where health care is available, the quality is often severely deficient, leaving its effectiveness well short of potential efficacy. One review concludes that, despite the claimed efficacy of primary health care interventions, the evidence is mixed on whether primary care clinics have any impact on population health ${ }^{8}$. This discouraging conclusion is attributed to the poor quality of public primary health care in many parts of the developing world. As long as such quality deficiencies persist, the estimates cited above of avoidable deaths through the utilization of effective interventions will remain purely hypothetical.

In practice, supply and demand side issues are not so easily separated. If the available health care is poor quality, it is not surprising to find there is little demand for it. There is evidence 
that demand does react to quality ${ }^{9}$. A detailed survey in a rural region of India finds very low use of public health facilities despite these being, in principle, free ${ }^{10}$. The reason is the very poor quality of care, although the private sector alternatives are also of dubious quality. It is futile to develop and implement policies that remove constraints on the demand for effective health care if there is little hope of such care being provided. Policy interventions on the demand and supply sides must progress in tandem.

\section{The poor make least use of} effective interventions

The first stylized fact about access to health care in the developing world is the underutilization of effective interventions. The second stylized fact is that utilization is lowest among the least well off. This is of concern from both efficiency and equity perspectives. The poor also tend to be the least healthy and most probably have the most to benefit from health care. The greatest health gains could be realized through concentrating marginal resources on treatment of the poor. The fact that those most in need make least use of health care is widely considered inequitable. Such concerns motivate the prioritization of programs that target the health care needs of the poor - primary care and child and maternal health interventions. Unfortunately, the evidence shows that there is pro-rich bias in the distribution of benefits even from these programs 11 .

The strongest evidence on the distribution of child and reproductive health interventions is from the Demographic Health Surveys (DHS) 12,13 . Households are ranked by an index of assets possessed e.g., refrigerator, sanitary toilet, safe drinking water, etc. Averaging across forty countries in which surveys were conducted in the mid-1990s, among the poorest $20 \%$ of households $56 \%$ of cases of childhood diarrhea are treated with oral rehydration compared with $71 \%$ of cases in the richest fifth of households 12 . Coverage is highest in sub-Saharan Africa, but so is inequality in coverage. Inequalities in immunization rates are even greater. On average (42 countries), the full immunization coverage rate is $66 \%$ in the richest quintile of households compared to only $38.5 \%$ in the poorest quintile 14 . The fact that one third of children in the better off households are not immunized is far from acceptable. Even worse is that 3 in 5 poor children lack such protection. Immunization rates are lowest in Latin America and the Caribbean, not reaching $60 \%$ even for the richest $20 \%$, but rich-poor disparities are greatest in Africa and South Asia. No more than a third of the poorest children in South Asia and sub-Saharan Africa are fully immunized. On average, the higher the overall coverage rate in a country, the greater is the rich-poor disparity. This suggests that the better off are first to benefit from marginal gains in coverage.

Socioeconomic disparities in the utilization of reproductive health services are still greater. On average (55 countries), women in the richest quintile are 5.2 times more likely to give birth under the supervision of a doctor, nurse, or midwife than the poorest fifth of women 13. Average coverage is lowest in South Asia and parts of subSaharan Africa, while inequalities are very strong in most regions with the exception of Eastern Europe and Central Asia. Inequalities in the use of contraceptives are of a similar magnitude. A woman in the richest $20 \%$ of households is 4.6 times more likely to use contraceptives than a woman in the poorest $20 \%$ (average across 49 countries) 13 .

Comparison of results from DHS conducted in the mid-1990s with those 3-5 years later reveal some encouraging examples of progress with respect to both average coverage rates and rich-poor disparities. Egypt, Kazakhstan, and Nepal have raised immunization coverage rates among the poor and reduced inequalities between the rich and poor 13. Egypt and Nepal increased full immunization for the poorest quintile by 26 and 22 percentage points respectively. For professionally attended deliveries, coverage has been raised and inequality reduced in Benin, Egypt, India, Nicaragua, Turkey, and Vietnam. In all cases, with the exception of Nicaragua, the fall in disparity is because the richest $20 \%$ were already close to $100 \%$ coverage in the first period. In Nicaragua, the rate for the poorest $20 \%$ apparently more than doubled (33 to $78 \%$ ) in a space of only 3 years. If this does represent a genuine increase, rather than some artifact of the data, it deserves close examination to draw lessons. Unfortunately, there are also many examples of little or no progress in tackling severe gaps in coverage and startling disparities in use. In Haiti, Bangladesh, and Nepal, the rate of medically attended deliveries among the poorest $20 \%$ increased by only $1-2$ percentage points from a base of only 2-3\%. In Peru, Cameroon, Ghana, Malawi, and Mali, the coverage rate for medically supervised births actually fell for the poorest fifth. Evidence from a non-DHS source suggests that income-related inequalities in access to health care increased in India between 1986-1987 and 1995-1996 15.

Besides the correction of market failures, public funding of health care is usually justified on a distributional basis. Equity, it is claimed, is 
inconsistent with the free market distribution of health care. Opinions may differ on the conception of equity underlying this position. Without touching on this issue, the empirical validity of this case for public intervention rests on whether it does in fact shift the health care distribution in the desired direction. The evidence shows, with a remarkable degree of consistency, that the poor actually receive a lesser share of public health expenditures in developing countries than the better off $16,17,18$. The evidence is summarized in Figure 1. In only seven countries do the poorest $20 \%$ of the population received at least their population share of total public health spending. Four of these seven are in Latin America (Argentina, Columbia, Costa Rica, and Honduras) and the others are in Asia (Malaysia, Sri Lanka, and Thailand). In most of the remaining cases, the poorest fifth enjoy between 10 and $15 \%$ of the public health subsidy. In Ecuador, Gansu (China), Guinea, and Nepal, the poor get less $10 \%$ of the subsidy.

There are differences in the distributions of different levels of care. With the exceptions of Ghana and Madagascar, the share of primary care received by the poor is greater than its share of the total public health subsidy. This implies that the utilization of public hospital services is very concentrated on the better off. Even for primary care, the share of the subsidy going to the poor reaches its population share in only eight countries. In most cases, there is a pro-rich bias in the distribution of public primary care even though this is exactly the type of health care that is supposed to best meet the health needs of the poor.

Admittedly, some of the benefit incidence evidence is somewhat crude. There is often no allowance for regional variation in expenditures, and quality differences are not taken into account. Correction of either of these deficiencies is likely to strengthen, rather than overturn, the conclusion that the better off get proportionately more. A detailed benefit incidence study in Asia provides some empirical support for this contention ${ }^{18}$. A more serious weakness is that the analysis informs on the incidence of public health expenditures, rather than the benefits of these expenditures. Even though the poor get a lower than proportionate share of the subsidy, the impact of the subsidy on the health of the poor can still be greater. With a lower level of health, the marginal health impact of health care should be greater for the poor. Further, the poor would be less able to afford health care in the absence of public care and so the net effect of the subsidy on their total consumption of health care should be greater than for the better off, for whom there is a larger crowding-out effect 19 . This hypothesis is consistent with evidence that public spending has no significant effect on health of the nonpoor but a positive marginal impact on the health of the poor $20,21,22$.

In summary, the poor make less use of health care than their better off compatriots. This is true for interventions such as child immunization and oral rehydration therapy, for which need is much greater among the poor. It is also true of primary care and publicly financed care. The distribution of health care in developing countries could be much more pro-poor than it currently is. However, even though the better-off use public programs more than the poor, these programs can still shift the distribution of health care in a pro-poor direction. It all depends on the counterfactual - what would be the distribution in the absence of these programs? Differential crowding-out effects can mean that public programs are used most by the better off but have the greatest positive impact on health care utilization of the poor. To identify the impact of public expenditure on health care utilization it is necessary to move from descriptive benefit incidence studies to evaluations of specific programs. This is more demanding of data. But careful evaluation is crucial to identification of policy initiatives that can raise utilization and to understanding how the impact varies with socioeconomic characteristics.

It is also important to distinguish between the distribution of health care at a given point in time and the distribution of marginal increments to health resources 23 . It is possible that the better off do best, on average, but that the marginal gains are concentrated on the poor. For many policy considerations, the distribution of the marginal gains is important. Unfortunately, there are few marginal benefit incidence analyses of health care.

\section{Why are effective interventions not utilized?}

Many factors are responsible for the underutilization of effective health care interventions in the developing world. Most obviously, economic resources are often insufficient to support the provision of essential services. The main recommendation of the WHO Commission on Macroeconomics and Health is for a substantial scaling up of expenditures on health care 7 . A second problem is that the available resources are not allocated to the most effective interventions, are geographically concentrated in large cities, and do not reach the poor. Despite the WHO Alma 
Ata Declaration, the bulk of public health expenditure continues to be absorbed by hospitalbased care delivered at some distance from poor rural populations 3,16 . Shifting the balance of resources further toward primary care would not necessarily have the desired impact on the level and distribution of population health, however $8,19,24$. There are major deficiencies in the quality of primary care delivered in many developing countries 8,25 .

Figure 1

Percentage of public health spending received by poorest $20 \%$.

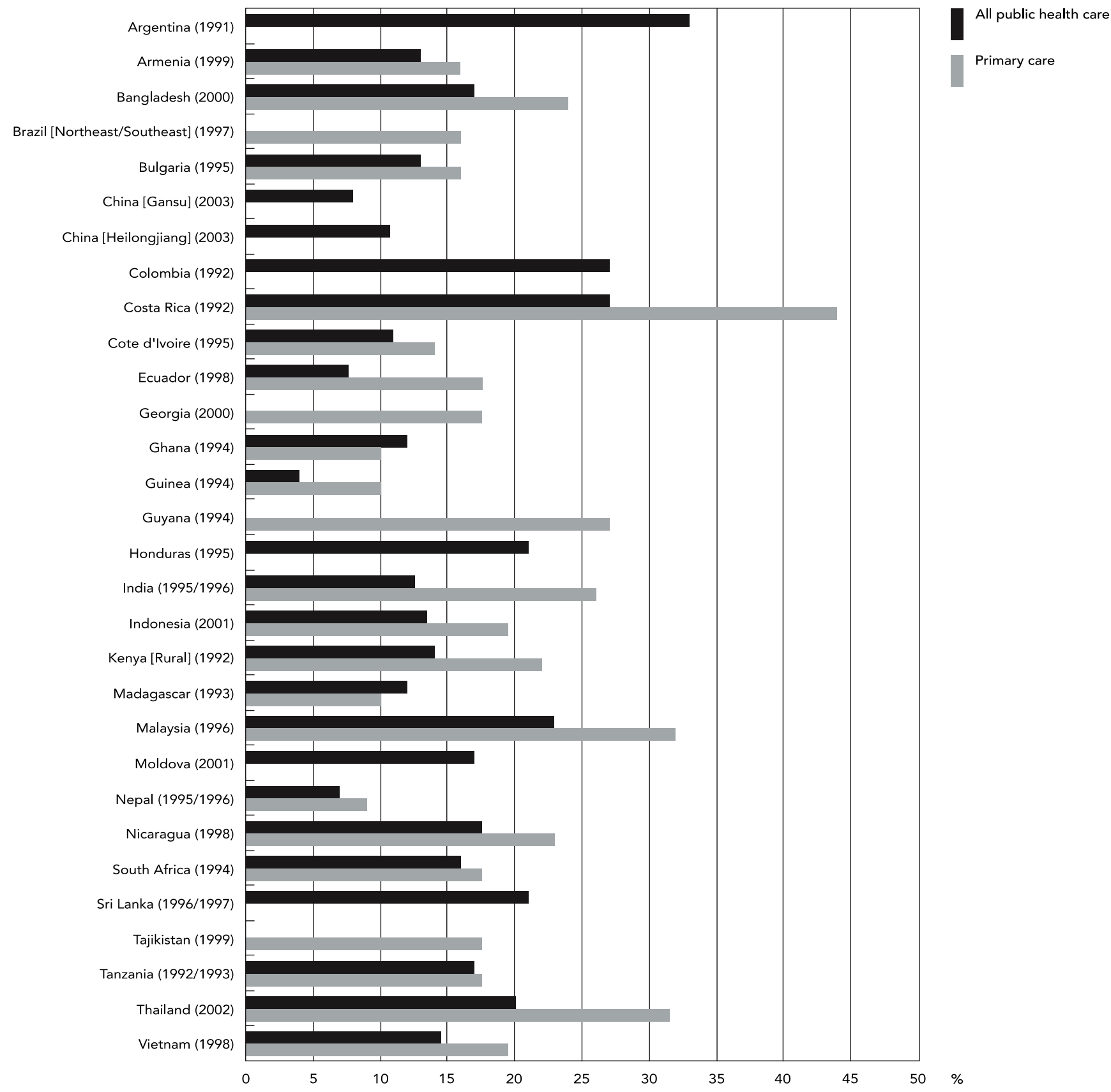

Source: Filmer 17 and O'Donnell et al. ${ }^{18 .}$ 
Insufficient resources, inappropriate allocation, and inadequate quality are major impediments to the delivery of effective health care that reaches the poor. The access problem cannot be solved without tackling each of these deficiencies. Although the importance of these supply side issues is not underestimated, the primary focus of this paper is the low demand for health care, where it is available. Two sets of factors may suppress demand, those that limit ability to consume and those that lower willingness to consume. In the economist's parlance, constraints and preferences. Constraints are determined by the income of the household, the charges made for health care, and costs incurred to reach health services. Preferences are influenced by culture, knowledge of the potential benefits of health care, and the quality of the services available.

\section{Constraints on the demand for health care}

\section{- Income}

The evidence reviewed in the section: Access to Effective Health Care in Developing Countries: Evidence shows a strong positive relationship between living standards and the utilization of health care. The relationship is not spurious. It holds after controlling for a multitude of other determinants of health care demand (see World Bank ${ }^{3}$ for a summary of evidence). For example, the probabilities that a woman receives prenatal care and receives a medically supervised delivery rise with income $26,27,28,29,30$. Similarly, the positive association between income and child immunization holds in multivariate analyses 31,32 .

In a market setting, a positive impact of income on consumption is expected. Prices are less of a barrier to use for those with greater purchasing power. It is a little more surprising to find the relationship emerging for public care. This is understandable once it is recognized that charges are normally made for public care in the developing world. In addition, with long distances to travel to reach health services, the non-price costs can be substantial. Monetary costs of care ensure that income is an important determinant of health care utilization and its dispersion.

The nature of health financing in the developing world, with heavy reliance on out-of-pocket payments, strengthens the relationship between health care utilization and income. Risk pooling and cross-subsidization, possible with pre-payments systems, break the dependency of health care utilization on current income. With out-ofpocket financing and limited access to credit, which is the norm in many poor countries, cur- rent household income is the binding constraint on health care use.

\section{- Prices}

Financing health care through out-of-pocket payments makes prices an important determinant of demand. In relative terms, the payments can be substantial. For example, for the poorest fifth of the population in Vietnam, the cost of a hospital visit is $22 \%$ of per capita annual household income net of food expenditure 33 . It would be surprising if such charges did not deter demand. The evidence confirms that they do 9 . There is some difference in the estimated strength of the relationship. Most studies of developing countries find health care to be price inelastic; demand falls less than proportionately to price $34,35,36,37,38$. A few obtain estimates of price elastic demand 39,40 .

There is strong empirical support for the proposition that the poor are more price sensitive than the better off 9,38,41,42. Increases in user charges will raise the share of health care consumed by the better off, unless effective mechanisms are implemented to shield the poor from these charges. Unfortunately, the general experience with fee waivers, particularly in Africa, is not encouraging 43 (see Strategies to Raise Utilization of Effective Interventions). User fees often effectively exclude the poor from essential services, while recovering only a fraction of costs 44 . Abolition of user fees in Uganda was associated with increase in utilization by the poor but this was not true in South Africa, where fees for maternal and child health services where removed 45 . The effect of price increases can be offset by quality improvements 9. There is evidence from Africa that if increased user charges are combined with reductions in travel time and improvements in quality, utilization can increase, even for the poor 41 .

Informal payments are substantial in many public health care systems. They are often greater than formal charges and may exist when official charges do not. These payments are particularly prevalent in the former Soviet Union and Eastern Bloc 46. In Armenia in 1999, 91\% of users were paying informally for public health care. In Azerbaijan and Poland, the figure was $78 \%$. But it is not an isolated phenomenon. In one region of rural India, the poor are paying almost as much to visit a "free" public health center as for a consultation with a private doctor 10 . 


\section{- Costs other than charges}

In addition to charges made by the health care providers, travel costs and foregone earnings are important costs of consuming health care in the developing world. In rural areas, the distances to health care facilities and the poor condition of roads mean that time, effort, and cost required to arrive at the point of delivery can be substantial. The evidence confirms the expected negative impact on health care utilization $26,47,48,49$. Halving the distance to public health facilities in Ghana was estimated to almost double their utilization rate 50 . The demand of the poor has been found to be more sensitive to travel time that of the better off in Cote d'Ivoire 41

\section{Determinants of preferences for health care}

\section{- Culture and gender issues}

Low demand for modern health interventions often derives from deep-rooted attitudes that reflect culture and social norms. One example are continued preferences for traditional over modern therapies. The fact that use of traditional therapies generally declines with income and education suggests that social norms are not inviolable. Adherence to norms is influenced by the socioeconomic environment.

Gender attitudes and roles are particularly important determinants of health seeking behavior. Raising access to maternal, reproductive, and child health interventions is a major challenge within societies that restrict the public lives of women. Again, the social is not completely divorced from the economic. There is evidence from Indonesia that the utilization of prenatal care increases with the control a woman exercises over household finances 51 . Causality is a moot point. In Africa, women make more use of public health care than men in the highest income group but the gender bias is the opposite in the lowest income groups 16 .

\section{- Knowledge and education}

Recognition of illness and the potential benefits of treatment are prerequisites for health care demand. Where a large proportion of the population is in poor health, this becomes the norm and illness is not easily recognized. If treatment coverage is low, there is less opportunity to learn of its benefit. The unfortunate outcome can be the continued toleration of illness and disease.

In India, 2 in 5 children are not fully immunized, despite the fact that immunization, at least in principle, is free. Almost a third of mothers said that they had not immunized their children because they were not aware of the benefits, and a further $30 \%$ claimed not to know where to go to get their child vaccinated ${ }^{52}$. A detailed study of a North Indian village demonstrates the importance of poor knowledge in diminishing demand for effective interventions 53 . Households are typically passive users of vaccines, accepting them when presented with them at doorstep but with little or no active demand. There is very poor knowledge of the link between vaccine and disease and the pace of learning of the relationship is slow. To raise utilization, it is important for the community to develop trust in the provider. Given the link between immunization and health is not immediately observable, trust can be developed through observation of the effectiveness of other services provided. The poor quality of many of the services provided impedes the development of trust.

There is substantial evidence from developing countries that the socioeconomic environment influences concepts of illness. Reported rates of illness are often higher among the better off than the poor 16,54,55. In rural Tanzania, better off households are more likely to recognize signs of illness in a child ( $<5$ years) 56 . Differences in knowledge are reflected in disparities in utilization. The better off are more likely to seek care for a child when sick, to take antimalarials and antibiotics for pneumonia, and to receive inpatient care.

\section{- Demand responses to poor quality}

Poor quality of health services is a major problem in many, but not all, developing countries 3,8 . Facilities open and close irregularly 10; absenteeism rates of doctors and nurses can be very high 10,57,58,59; staff can be hostile, even violent to patients 60; misdiagnosis is not uncommon 3; medicines are all too often unavailable, sometimes due to staff pilfering for use in private practice 3,61 ; and there is inappropriate prescribing and treatment ${ }^{3}$. Deficiencies in quality have direct implications for access to effective health care. Further, one expects that demand will diminish in response to the poor quality of the care offered. The evidence confirms the hypothesis ${ }^{9}$. A decline in quality of public health care in Ghana was associated with $40 \%$ fall in utilization within only five years (1979-1983) 50.

Low quality of public primary health care can result in patients forgoing ("bypassing") care at the nearest facility and seeking care at a higherlevel public facility or in the private sector 8,62 . In Sri Lanka, the lower the quality of the public primary care facilities, the more likely it is that 
patients will bypass them ${ }^{63}$. There is similar evidence from Pakistan, Indonesia, and El Salvador 8,62 . Linked surveys of both health care utilization and facilities in a rural Rajasthan (India) find very low use of public health care, despite the fact that there are no formal charges 10 . The population is mainly using private care. This is in response both to the informal charges levied for public care and its very low quality. The survey finds staff absentee rates of $36-45 \%$, sub health centers closed during regular hours $56 \%$ of the time and following no predictable pattern of opening hours. Utilization is lower at centers that open less often.

Low utilization of poor quality public care is wasteful of resources and imposes costs on patients that seek care further from home. From the perspective of patient health, individuals choosing to forgo low for higher quality care might not be considered a problem. Unfortunately, the alternative care is often also of dubious quality. The Rajasthan surveys find that $41 \%$ of "doctors" operating in the private sector admit to having no medical degree, $18 \%$ have no (para-)medical training, at all and $17 \%$ have not even graduated from high school 10 . There is also evidence of inappropriate treatment; $68 \%$ of patients are given an injection on a visit to a private doctor $(32 \%$ in the public sector). It is the convenience of the private sector - people know they will find the clinic open and staffed - rather than the effectiveness of the care on offer that attracts patients away from the public sector.

Demand is not as responsive to poor quality as one might expect. Despite the appalling picture of quality in Rajasthan both in the public and private sector, households spend a large fraction ( $7 \%$ on average) of their budget on health care and they do not complain about the quality of health care 10. Expectations of health services are very low. Relying on demand side pressures to provoke improvements in quality of care would be a long and painful process. Health care demand of the poor is less sensitive to quality than that of the better off 50 . This suggests that public resources could be directed to the benefit of the poor by providing lower quality, but minimal standard, subsidized care alongside a private alternative. This is not consistent with the evidence, presented in Access to Effective Health Care in Developing Countries: Evidence, which shows that the better off invariably get the largest share of the public health subsidy. One explanation is that the better off get better quality care, even within the public sector. In Africa, there is some confirmation of this proposition 16,50.

\section{Strategies to raise utilization of effective interventions}

Raising the utilization of effective health care in the developing world requires more money for health care. It requires that spending is directed to the most effective programs and interventions and that the geographic distribution of these programs does not grossly mismatch that of the population. It requires reforms to management, regulatory, and political mechanisms such that providers face strong incentives to deliver quality health care. These measures are necessary conditions for solving the access problem. They will ensure that truly effective health care is available. This is not sufficient. Individuals must be willing to use effective preventive and treatment interventions and they must have the purchasing power to realize this desire. How can the demand for health care be increased within resource poor settings?

\section{Extending health insurance coverage}

Financing health care through out-of-pocket payments strengthens the constraining effects of current income and price on utilization. The constraint is further tightened by the lack of borrowing opportunities. Pre-payment mechanisms, which pool risks across individuals, and credit schemes, which allow risks to be smoothed across time, weaken the household budget constraints on health care demand. There have been repeated calls for a reduction in the reliance on out of pocket financing in developing countries 7,64. According to Organization for Economic Cooperation and Development/World Health Organization (OECD/WHO) DAC guidelines 64, the development of equitable financing through increasing pre-payment and risk pooling is one of four priorities for the development of a propoor health system delivering quality, accessible health services to the poor. Unfortunately, the legal, tax, and labor market institutions of lowincome countries are usually inconsistent with universal pre-payment financing mechanisms. Employment based social insurance is limited to the formal sector, which can be relatively small and excludes the less well off. Tax finance is limited by the narrowness of the tax base.

The process of economic development regulates the movement to universal coverage. Policy initiatives can accelerate the process, however. Thailand introduced universal coverage in 20012002, extending coverage to those outside the formal sector for a minimal charge of 30 Baht (70 US cents) per visit 65 . This is funded from general tax revenues. The impact on utilization is not yet 
known. Extending coverage to the whole population outside of the contributory schemes of the formal sector is expensive. A more feasible route for many low-income countries is to use the available tax revenues to extend coverage to the poor. This imposes a lower financial burden but is administratively more demanding, requiring that the poor be identified through a means test. In Colombia, the poor are covered against the costs of primary care and catastrophic events under a scheme funded by all levels of government and through cross-subsidization from contributory schemes 66 . This extension raised coverage of the poorest income quintile from 3-8\% in 1993 to $47 \%$ in 1997 . Insurance in Vietnam started, in 1993, with compulsory coverage of formal sector employees and voluntary cover targeted at school children and students. Insurance cover raised the service contact rate and shifted utilization toward care in hospitals and health centers that are covered by the scheme 67 . Recently, provinces have been mandated to enroll the poor in the health insurance scheme.

Rather than extend insurance cover to the poor directly, this might be achieved indirectly by granting cover based on some characteristic, such as age, that is correlated with poverty. This has the advantage of being administratively easier to implement than a means test, while respecting financial constraints that rule out full population coverage. Amongst the poor, ill health is concentrated on children. In the poorest $20 \%$ of countries, children ( $<15$ years) account for $50 \%$ of all deaths, compared to $4 \%$ in the richest $20 \%$ of countries 68 . Rich-poor disparities in health are greatest among the young. This suggests that an age-targeted poor oriented health policy should focus on the young 69 . Egypt, even more than Vietnam, has targeted health insurance coverage on school children. The policy has raised utilization and reduced rich-poor disparities in use among school children 70 . One significant problem is that inequalities in utilization between children attending and not attending school increased. Those not attending school tend to be poorer.

Pooling of risks at lower levels, such as the community, is less constrained by the structure of the economy. There is increasing interest in community financing schemes that are now operating in parts of Africa and Asia 71. These are managed by community groups or nongovernmental organizations (NGOs), and essentially pool health expenditure risks at the community level. They can be integrated with existing community credit/micro-finance schemes. Households pay premiums or these are taken from cooperatives sales. Payment can be timed to coincide with periods of cash flow/harvest. In a few cases, the government contributes a subsidy. Besides administrative capacity, the existence and development of community solidarity is an essential ingredient of success 3,71,72.

The Commission on Macroeconomics and Health recommends that out-of-pocket payments be channeled into community financing schemes to cover community-based delivery of basic curative care, not essential services that are to be universally available and financed centrally 7 . This is to be promoted through cofinancing from the national government, backed by donors. Examples of successful community financing schemes suggest these ideas should be given serious consideration. However, experience of application is still rather limited. Evaluations need to be conducted to better identify the ingredients of success, the consequences for health care use and household living standards, and the long-term viability of the schemes 64 .

\section{Pro-poor price subsides}

The extension of health insurance cover is a long-term goal. At low levels of development, a more feasible policy is to maintain reliance on out-of-pocket payments but to grant exemptions to groups, principally the poor, for which price is a major deterrent to use. Interventions that generate external benefits, such as immunization against infectious disease, should also be exempted. In principle, this approach allows the public expenditure subsidy to be concentrated on those most in need financially, but also medically to the extent that poverty and ill health coincide, rather than being dissipated across the whole population, or even concentrated on the better off as is indicated by the evidence reviewed in Access to Effective Health Care in Developing Countries: Evidence. The challenges lie in the identification of the poor and the provision of appropriate incentives to providers.

Criteria for exemptions must be decided. In addition to the currently poor, those vulnerable to falling into poverty through ill health may be targeted. For example, exemptions might be offered to the poorest quintile, indigenous people, migrants, adolescents, refugees, and the socially excluded e.g., slum-dwellers 64 . Verification of eligibility based on such criteria is a considerable administrative task.

There are many examples of fee waiver schemes that have failed to protect the poor and to ensure their access to health care 69,73 . Exemption criteria are often vague, entitlement based on income is difficult to assess, little direction is given on implementation, and potential beneficiaries have poor knowledge of entitlement 74 . 
The result is that local administrators, often the providers of care, have much discretion and little or no incentive to grant exemptions. In fact, where providers are not compensated for forgone fee revenue, there is an incentive to reject claims for exemptions. Africa, in particular, provides many examples of dysfunctional fee waiver schemes $69,75,76$. One study found one in four of those using care in Zambia were incorrectly denied an exemption 73 .

Not all the news is bad. Successful fee waiver schemes have solved the difficulties of verification of entitlement and provider incentives. Entitlement cards, issued on the basis of income and granting exemption from user charges at public facilities, separate responsibility for verification of entitlement from that for provision of care. Thailand operated such a scheme prior to the introduction of universal coverage. Crucially, providers were compensated from a special budget. There was estimated to be $20 \%$ leakage (subsidies to non-poor) from the scheme and $65 \%$ of poor were covered 77 . A similar scheme has operated in Indonesia since 1997. In this case, providers receive lump sum compensation based on the expectation of induced demand, rather than in relation to actual utilization of cardholders. The distribution and utilization of health cards is concentrated on the poor, although there is leakage 78 . The cards raise utilization of outpatient care by the poor and cause both the poor and non-poor to substitute public for private care. Utilization rises because of the price effect on cardholders, but the supply response to the budget supplement and the consequent improvement in quality has the largest impact on utilization. The non-poor largely capture this effect. Tying provider budgets more closely to the utilization of cardholders would increase target efficiency.

A health card gives entitlement to care. An alternative is to issue vouchers for the purchase of medical goods and services. In southern Tanzania, pregnant women and mothers of young children are given vouchers that can be exchanged for a discount on the price of a treated mosquito net. Combined with social marketing, the vouchers help raise the average level and reduce the richpoor disparities in use of nets 79. In Managua, Nicaragua, female sex workers are issued vouchers that can be exchanged for consultations at private, NGO, and public clinics 80 . Incidence of sexually transmitted diseases has fallen by $65 \%$ among users of vouchers. As these examples suggest, vouchers are most feasible where demand is predictable. Nevertheless, potential applicability is much wider than is currently realized. Vouchers not only give providers a financial incentive to respond to demand, they can be used to promote competition and enhance quality. Increased use of vouchers is consistent with the switch in the role of the state from provider to steward in the health care sector 7,64 .

Government need not administer targeting schemes. Responsibility can be given to the community and NGOs 69. In a region of Cambodia, hospital care for the poor is paid for from a fund that is financed by aid organizations and administered by a local NGO 81 . The NGO verifies eligibility. Hospital fees of eligible patients are covered from the fund and their travel expenses are reimbursed. The impact of utilization has not been established, but more than $40 \%$ of hospital users are from the most deprived social group.

A key point that emerges from the fee waiver literature is that it is very important to pay attention to the supply side. Providers must be given incentives to meet the demand created by price subsidies. A fund must be designated and financed to pay suppliers, including those within the public sector, for the care of exempted groups. Other key ingredients of a successful fee waiver policy are: concrete eligibility criteria; independent eligibility verification through local/central officials or NGOs and not service providers; and regular review of exemption status 69,73.

\section{Using cash rewards to raise utilization}

Insurance and price subsidies weaken financial deterrents to health care use. The potency of this strategy is dependent upon the importance of price in determining health care utilization. If poor knowledge, education, or cultural factors are mainly responsible for low utilization, removing price barriers will have little impact on use. But economic incentives may still be a potent means of overcoming non-economic barriers to utilization. Financial rewards can be used to induce changes in health seeking behavior. In Latin America, there has been increasing use of policies that offer households cash conditional on participation in programs that develop human capital. In relation to health, the approach is practical for preventive interventions, such as immunization, child growth monitoring, and antenatal care ${ }^{3}$.

These cash transfers are typically targeted at the poor, either directly through a means test and/or indirectly e.g., through geographic targeting of regions with high concentrations of poverty. Cash payments can be paid directly to women. This increases the financial autonomy of women, which may be exploited to direct household spending toward services, such as maternal and child health care, to which women attach greater 
priority. Micro-credit schemes may be expected to have a similar effect, although the evidence in support of this is ambiguous 82 .

Evidence from evaluations of conditional cash transfers confirms positive effects on utilization ${ }^{3}$. Immunization rates have been raised in Nicaragua and Honduras. Health service use, e.g., prenatal care, increased substantially in Brazil, Honduras, Mexico, and Nicaragua. In Honduras and Nicaragua, the largest impacts were on the utilization by the poorest households. These are encouraging results and suggest that experimentation with and evaluation of conditional cash transfers ought to be extended to other parts of the world. As with fee waivers, attention needs to be paid to the incentives for providers to respond to the induced demand with quality care. To secure the permanence of changes in health seeking behavior, financial incentives should be combined with information on the benefits of care.

This is a promising area of policy activity. Its potential is, however, limited to preventive care interventions, the need for which is homogeneous or at least can be easily verifiable through observable demographics.

\section{Lowering the barrier of distance}

Lowering the barrier of distance requires either taking people to services or services to people. Improved transport systems reduce the cost of reaching health care and raise the ratio of facilities to catchment area population ${ }^{3}$. Road building is expensive and is not under the control of health sector policymakers. More feasible are schemes that lower the price of travel for health care or provide credit to cover travel expenses. In Africa, community administered and financed funds facilitate travel for emergency obstetric care and provide emergency interest free loans to cover the cost 83,84 . There is evidence of a positive impact on emergency referral rates 3 .

The close-to-the-client system proposed by the Commission on Macroeconomics and Health is founded on the logic of bringing services closer to populations. Provision at the level of the community requires either raising finance at this level or allocating funds down to this level. With community financing, risk pooling is inevitably limited. On the other hand, distribution of funds in relation to the geographic distribution of health needs is a difficult administrative and political exercise. It is demanding of data and vulnerable to distortion through political interference. Bolivia provides a model of decentralization that has been successful in directing resources toward the poor and improving health outcomes 3 .

\section{Conclusion}

The literature convincingly demonstrates the existence of an access problem. Effective health care interventions are underutilized in the developing world, and income-related disparities in use are large. Causes of the problem are also identified: insufficient system resources; inappropriate allocation of resources across levels of care, programs, and regions; inadequate quality; insufficient household incomes; lack of access to credit; prohibitive charges (formal and informal); travel costs; cultural barriers to the acceptability of services; and misperceptions of illness and the effectiveness of care. Solutions, at a very general level, must address one or more of these causes. The difficulty lies in the design of detailed policy initiatives that tackle root problems within usually severe economic, institutional, and political constraints.

Solutions to the access problem need to be further developed at a general strategic level, but more crucially at the level of detailed policy measures. The Commission on Macroeconomics and Health 7, OECD/WHO 64, and the World Bank 3 have all made important contributions to the development of broad strategies. There is consensus support for universal access to essential services, priority to services close to the community but with measures to improve the quality of care, reduced role for the state in the provision of care and strengthening of its stewardship role, targeting of diseases of poverty, and more effective protection of the poor from user charges. These are really recommendations of policy goals rather than policy instruments. While there is some consensus on the general lines of a strategy for improving access to health care, details of the precise policy measures required to implement such a strategy are more difficult to identify. This is understandable. A general strategy can be defined at the global level, while policy measures should be heterogeneous, varying with the local conditions in which they are implemented. This said, there is scope for more precision in the advocacy of policies to raise health care utilization and to narrow disparities in its distribution. This precision requires strengthening of the evidence base.

Recent initiatives in health financing, price subsidies, and poverty alleviation programs are promising. Community financing, micro-credit schemes, entitlement cards, vouchers, and conditional cash transfers have all been demonstrated to raise health care utilization (see Strategies to Raise Utilization of Effective Interventions). But their application is still very limited, both geographically and with respect to the services 
covered. The common characteristic of these initiatives is that they work through demand side economic incentives. Community financing and fee waivers implemented through health cards remove, or at least reduce, the constraints of income and price. Micro-credit schemes relax the income constraint from current to lifetime income. Vouchers reduce the price constraint on demand. Conditional cash transfers provide a positive financial incentive to consume health care interventions. Community financing, microcredit, and fee waivers provide different degrees of insurance against unforeseen expenditures, although the nature of the risk pooling is different in each case. Community financing and microcredit, with relatively small risk/saving pools may find it difficult to cover against high cost interventions. Health cards and targeted health insurance are financed at the national level and can cover such risks. Vouchers and conditional cash transfers are essentially price incentives to induce demand for preventive care for which there is a predictable, easily verifiable need. There may be scope for extending the use of vouchers to low cost, high frequency curative care, such as primary care for small children. Further consideration should be given to the combination of these instruments to cover different needs for preventive and curative, predictable and unpredictable, and high and low cost care.

Advocacy of these initiatives is necessarily tentative while the evidence base on their effectives remains so thin. Implementation should be accompanied by evaluation for two main reasons. First, post-evaluation, the design of a scheme can be modified to improve effectiveness. Second, the evaluation provides lessons for implementation elsewhere. The OECD/WHO DAC guidelines 64 list social impact analysis as a principal role of development agencies in the realization of financing systems that improve access. The impact on the average utilization of health services should be identified and differential effects with socioeconomic characteristics tested.

\section{Resumo}

Nos países em desenvolvimento, as intervenções efetivas na saúde são subutilizadas, enquanto a utilização mostra disparidades associadas à renda. O autor resume as evidências sobre esse problema de acesso e identifica as causas existentes no lado da demanda. Em seguida, o autor analisa estratégias amplas para enfrentar o problema de acesso por meio de mudanças nos incentivos econômicos. O autor argumenta que é necessário ir além da identificação de estratégias amplas para elaborar e avaliar medidas políticas específicas. Somente por meio da experimentação e da avaliação poderemos aprender como aumentar a utilização dos cuidados em saúde, particularmente entre os pobres no mundo em desenvolvimento.

Acesso aos Serviços de Saúde; Países em Desenvolvimento; Eqüidade 


\section{References}

1. Penchansky R, Thomas JW. The concept of access: definition and relationship to consumer satisfaction. Med Care 1981; 19:127-40.

2. Shengelia B, Murray CJL, Adams O. Beyond access and utilization: defining and measuring healthsystem coverage. In: Murray CJL, Evans DB, editors. Health systems performance assessment: debates, methods and empiricism. Geneva: World Health Organization; 2003. p. 221-34.

3. World Bank. The millennium development goals for health: rising to the challenges. Washington DC: World Bank; 2004.

4. Jones G, Steketee RW, Black RE, Bhutta ZA, Morris SS; Bellagio Child Survival Study Group. How many child deaths can we prevent this year? Lancet 2003; 362:65-71.

5. Hill Z, Kirkwood B, Edmond K. Family and community practices that promote child survival, growth and development. London: Public Health Intervention Research Unit, Department of Epidemiology and Population Health, London School of Hygiene; 2003.

6. Aguilar AM, Alvarado R, Cordero D, Kelly P, Zamora A, Salgado R. Mortality survey in Bolivia: the final report. Investigating and identifying the causes of death for children under five. Arlington: Basic Support for Institutionalizing Child Survival; 1998. (Technical Report).

7. Commission on Macroeconomics and Health. Macroeconomics and Health: investing in health for economic development. Geneva: World Health Organization; 2001.

8. Filmer D, Hammer J, Pritchett L. Weak links in the chain: a diagnosis of health policy in poor countries. World Bank Res Obs 2000; 15:199-224.

9. Alderman H, Lavy V. Household responses to public health services: cost and quality tradeoff. World Bank Res Obs 1996; 11:3-22.

10. Banerjee A, Deaton A, Duflo E. Health care delivery in rural Rajasthan. Econ Polit Wkly 2004; 39:944-9.

11. Gwatkin DR. Overcoming the inverse care law: designing health care programs to serve disadvantaged population groups in developing countries. Washington DC: World Bank; 2001.

12. Gwatkin DR, Rustein S, Johnson K, Pande RP, Wagstaff A. Socioeconomic differences in health, nutrition and population. Washington DC: World Bank, Health, Population and Nutrition Group; 2000.

13. Gwatkin DR, Rustein S, Johnson K, Pande RP, Wagstaff A. Initial country-level information about socioeconomic differentials in health, nutrition and population. Washington DC: World Bank, Health, Population and Nutrition Group; 2003.

14. Gwatkin DR, Devishwar-Bahl G. Immunization coverage inequalities: an overview of socioeconomic and gender differentials in developing countries. Washington DC: World Bank; 2001.

15. Sen G, Aditi I, Asha G. Structural reforms and health equity: a comparison of the NSS Surveys, 1986-87 and 1995-96. Econ Polit Wkly 2002; 37:1342-52.

16. Castro-Leal F, Dayton J, Demery L, Mehra K. Public spending on health care in Africa: do the poor benefit? Bull World Health Organ 2000; 78:66-74.
17. Filmer D. The incidence of public expenditures on health and education. Background note for the World Development Report 2004: making services work for the poor. Washington DC: World Bank; 2003.

18. O'Donnell O, van Doorslaer E, Rannan-Eliya RP, Somanathan A, Adhikari SR, Harbianto D, et al. The incidence of public spending on healthcare: comparative evidence from Asia. World Bank Econ Rev 2007; 21:93-123.

19. Filmer D, Hammer J, Pritchett L. Weak links in the chain II: a prescription for health policy in poor countries. World Bank Res Obs 2002; 17:47-66.

20. Bidani B, Ravallion M. Decomposing social indicators using distributional data. J Econ 1997; 77:12540.

21. Gupta S, Verhoeven M, Tiongson ER. Public spending on health care and the poor. Health Econ 2003; 12:685-96.

22. Wagstaff A. Child health on a dollar a day: some tentative cross-country comparisons. Soc Sci Med 2003; 57:1529-38.

23. Lanjouw P, Ravallion M. Benefit incidence, public spending reforms and the timing of program capture. World Bank Econ Rev 1999; 13:257-73.

24. Filmer D, Pritchett L. The impact of public spending on health: does money matter? Soc Sci Med 1999; 49:1309-23.

25. World Health Organization. World health report 2000. Geneva: World Health Organization; 2000

26. Wong EL, Popkin BM, Guilkey DK, Aking JS. Accessibility, quality of care and prenatal care use in the Philippines. Soc Sci Med 1987; 24:927-44.

27. Schwartz J, Akin J, Popkin B. Price and income elasticities of demand for modern health care: the case of infant delivery in the Philippines. World Bank Econ Rev 1988; 2:49-76.

28. Panis C, Lillard L. Health inputs and child mortality. J Health Econ 1994; 13:455-89.

29. Guilkey DK, Riphan R. The determinants of child mortality in the Philippines: estimation of a structural model. J Dev Econ 1998; 56:281-305.

30. Barbhuiya MA, Hossain S, Hakim MM, Rahman SM. Prevalence of home deliveries and antenatal care coverage in some selected villages. Bangladesh Med Res Counc Bull 2001; 27:19-22.

31. Steele F, Diamond I, Amin S. Immunization uptake in rural Bangladesh: a multilevel analysis. J R Stat Soc Ser A Stat Soc 1996; 159:289-99.

32. Gage AJ, Sommerfelt AE, Piani AL. Household structure and childhood immunization in Niger and Nigeria. Demography 1997; 34:295-309.

33. World Bank. Growing healthy? A review of Vietnam's health sector. Hanoi: World Bank; 2001.

34. Heller P. A model of the demand for medical and health services in Peninsular Malaysia. Soc Sci Med 1982; 16:267-84.

35. Akin J, Griffin CC, Guilkey DK, Popkin B. The demand for primary health care services in the Bicol region of the Philippines. Economic Development and Cultural Change 1986; 34:755-82.

36. Gertler P, Locay L, Sanderson W. Are user fees regressive? The welfare implications of health care financing proposals in Peru. J Econ 1987; 36:67-88. 
37. Sauerbron R, Nougtara A, Latimer E. The elasticity of demand for health care in Burkina Faso: differences across age and income groups. Health Policy Plan 1994; 9:186-92.

38. Mocan HN, Tekin E, Zax JS. The demand for medical care in urban China. World Development 2004; 32:289-304.

39. Chernichovsky D, Meesook O. Utilization of health services in Indonesia. Soc Sci Med 1986; 23:611-20.

40. De Bethune X, Alfani S, Lahaye JP. The influence of abrupt price increases on health service utilization: evidence from Zaire. Health Policy Plan 1989; 4:76-81.

41. Gertler P, van der Gaag J. The willingness to pay for medical care: evidence from two developing countries. Baltimore: John Hopkins University Press; 1990.

42. Litvack J, Bodart C. User fees plus quality equals improved access to health care: results of a field experiment in Cameroon. Soc Sci Med 1993; 37:369-83.

43. Gilson L. The lessons of user fee experience in Africa. Health Policy Plan 1997; 12:273-85.

44. Ahrin-Tenkorang D. Mobilizing resources for health: the case for user fees revisited. Geneva: Commission on Macroeconomics and Health; 2000. (CMH Working Paper Series, WG3:6).

45. Schneider H, Gilson L. The impact of free maternal health care in South Africa. In: Berer M, TK Sundari $\mathrm{R}$, editors. Safe motherhood initiatives: critical issues. Oxford: Blackwell Science; 1999. p. 93-101.

46. Lewis M. Who is paying for health care in Europe and Central Asia? Washington DC: World Bank; 2000.

47. Mwabu G, Ainsworth N, Nyamete A. Quality of medical care and choice of medical treatment in Kenya: an empirical analysis. J Hum Resour 1993; 28:838-62.

48. Lavy V, Strauss J, Thomas D, de Vreyer P. Quality of care, survival and health. J Health Econ 1996; 15:333-57.

49. Thomas D, Lavy V, Strauss J. Public policy and anthropometric outcomes in Cote d'Ivoire. J Public Econ 1996; 61:155-92.

50. Lavy V, Germain J-M. Quality and cost in health care choice in developing countries. Washington DC: World Bank; 1994. (Lsms Working Paper, 105).

51. Beegle K, Frakenburg E, Thomas D. Bargaining power within couples and the use of prenatal and delivery care in Indonesia. Stud Fam Plann 2001; 32:130-46.

52. Pande R, Yazbeck A. What's in a country average? Wealth, gender, and regional inequalities in immunization in India. Soc Sci Med 2003; 57:2075-88.

53. Das J, Das S. Trust, learning and vaccination: a case study of a North Indian village. Soc Sci Med 2003; 57:97-112.

54. Strauss J, Thomas D. Health, nutrition and economic development. J Econ Lit 1998; 36:766-817.

55. Sadana R, Tandon A, Murray CJL, Serdobova I, Cao Y, Xie WJ, et al. Describing population health in six domains: comparable results from 66 household surveys. Geneva: World Health Organization; 2002. (Global Programme on Evidence for Health Policy Discussion Paper, 43).
56. Schellenberg JA, Victora CG, Mushi A, de Savigny D, Schellenberg D, Mshinda H, et al. Inequities among the very poor: health care for children in rural southern Tanzania. Lancet 2003; 361:561-6.

57. Chaudhury N, Hammer J, Kremer M, Muralidharan $\mathrm{K}$, Rogers H. Teachers and health care providers absenteeism: a multi-country study. Washington DC: World Bank Development Research Group; 2003.

58. Chaudhury N, Hammer J. Ghost doctors: absenteeism in Bangladeshi health facilities. Washington DC: World Bank Development Research Group; 2003.

59. World Bank. World Development Report 2004: making services work for the poor. Washington DC: World Bank; 2004.

60. Dodd R, Munck L. Dying for change: poor people's experience of health and ill-health. Geneva: World Health Organization/Washington DC: World Bank; 2001.

61. McPake B, Asiimwe D, Mwesiqye F, Ofumbi M, Ortenblad L, Streefland P, et al. Informal economic activities of public health workers in Uganda: implications for quality and accessibility of care. Soc Sci Med 1999; 49:849-65.

62. Akin J, Hutchinson P. Health-care facility choice and the phenomenon of bypassing. Health Policy Plan 1999; 14:135-51.

63. Samrasinghe D, Akin J. Health strategy and financing study: final report. Colombo: Ministry of Health and Women's Affairs; 1994.

64. Organization for Economic Cooperation and Development/World Health Organization. DAC guidelines and reference series - poverty and health. Paris: Organization for Economic Cooperation and Development/World Health Organization; 2003.

65. Suratdecha C, Saithanu A, Tangcharoensathien V. Reaching the poor: the case of universal coverage in Thailand, 2004. http://www.worldbank. org/wbi/healthandpopulation/RTPmaterials / Reaching\%20the\%20Poor/Session\%205B-Pres/ Chutima.ppt (accessed on 10/May/2004).

66. Castaneda T. Targeting health insurance to the poor in Colombia, 2004. http://www.worldbank. org/wbi/healthandpopulation/RTPmaterials / Reaching\%20the\%20Poor/Session\%207A-Pres/ Castaneda\%20.ppt (accessed on 10/May/2004).

67. Wagstaff A, Pradhan M. Evaluating the impacts of health insurance: looking beyond the negative. Washington DC: World Bank, Health, Population and Nutrition Group; 2003.

68. Murray CJL, Lopez AD. The global burden of disease: a comprehensive assessment of mortality and diseases, injuries and risk factors in 1990 and projected to 2020. Cambridge: Harvard School of Public Health; 1996.

69. Gwatkin DR. Targeting health programs to reach the poor. Washington DC: World Bank; 2000.

70. Yip W, Berman P. Targeted health insurance in a low income country and its impact on access and equity in access: Egypt's school health insurance. Health Econ 2001; 10:207-20. 
71. Hsiao W. Unmet health needs of two billion: is community financing a solution? Washington DC: Commission on Macroeconomics and Health; 2001. (Health, Nutrition and Population Discussion Paper).

72. Hsiao W, Lui Y. Health care financing: assessing its relationship to health equity. In: Evans T, Whitehead M, Diderichsen F, Bhuyia A, Wirth M, editors. Challenging inequalities in health: from ethics to action. New York: Oxford University Press; 2001. p. 268-89.

73. Tien M, Chee G. Literature review and findings: implementation of waiver policies. Washington DC: Partners for Health Reformplus; 2002.

74. Russell S, Gilson L. User fee policies to promote health service access for the poor: A wolf in sheep's clothing? Int J Health Serv 1997; 27:359-80.

75. Nolan B, Turbat V. Cost recovery in public health services in Sub-Saharan Africa. Washington DC: World Bank Economic Development Institute; 1995.

76. Gilson L, Russell S, Buse K. The political economy of user fees with targeting: developing health financing policy. J Int Dev 1995; 7:369-401.

77. Khoman S. Rural health care financing in Thailand. In: Schieber GJ, editor. Innovations in health care financing: proceedings of a World Bank conference. Washington DC: World Bank; 1997. p. 18393.
78. Saadah F, Pradhan M, Sparrow R. The effectiveness of the health card as an instrument to ensure access to medical care for the poor during the crisis. Washington DC: World Bank; 2001.

79. Nathan R, Masanja H, Mshinda H, Schellenberg JA, de Savigny D, Lengeler C, et al. Mosquito nets and the poor: can social marketing redress inequities in access? Trop Med Int Health 2004; 9:1121-6.

80. Gorter A, Sandiford P, Segura Z, Villabella C. Improved health care for sex workers: a voucher programme for female sex workers in Nicaragua. Research for Sex Work Newsletter 1999; (2):11-3.

81. Hardeman W, van Damme W, van Pelt M, Por I, Kimvan H, Meessen B. Access to health care for all? User fees plus a Health Equity Fund in Sotnikum, Cambodia. Health Policy Plan 2004; 19:22-32.

82. Pitt MM, Khandker SR, McKernan SM, Abdul Latif M. Credit programs for the poor and reproductive behavior in low-income countries: are the reported causal relationships the result of heterogeneity bias? Demography 1999; 36:1-21.

83. Samai O, Sengeh P. Facilitating emergency obstetric care through transportation and communication, Bo, Sierra Leone. The Bo PMM Team. Int J Gynaecol Obstet 1997; 59 Suppl 2:S157-64.

84. Eissen E, Effene D, Sabitu K. Community loan funds and transport services for obstetric emergencies in Northern Nigeria. Int J Gynaecol Obstet 1997; 59 Suppl 2:S48.

Submitted on $19 /$ Sep/2006

Approved on 25/Jan/2007 